\title{
EVALUATION OF RESEARCH INSTITUTES OF THE NATIONAL ACADEMY OF SCIENCES OF UKRAINE: PROBLEMS WITH IMPLEMENTATION OF THE 'BEST PRACTICES'
}

IGOR YEGOROV

DOI: $10.22163 /$ fteval.2019.336

\section{INTRODUCTION}

$\mathrm{U}$ raine is going through difficult period of reforms, which comprise all spheres, including Science and Technology (S\&T). It is important to stress that the economic situation has changed substantially in recent years. Some high-tech segments of the economy have disappeared along with design bureaux and research institutes, which worked for them. The branch sector has virtually collapsed without state financial support and the lack of orders from industry. In the past, attempts to conduct really profound reforms of the RGD sector were not systematic, as the country suffers from permanent political instability and changes of the governments (European Commission, 2016). The best part of Ukrainian science has been preserved within the National Academy of Sciences of Ukraine (NASU) and five other state-sponsored academies. The institutes of these academies of sciences have direct state financial support. These academies received more than three quarters of all state financing for $R \& D$ in recent years, while the National Academy of Sciences receives more than $50 \%$ of the state money on R\&D alone (Naukova..., 2017). However, principles of management and criteria for evaluation of research establishments remained mainly unreformed; indicators of research efficiency went down in recent decades. That is why the state is very interested in a proper evaluation of research institutes and aims for changes within the national research system, based on new approaches, which could open the way for reforms in the RGD sphere.

The paper deals with the results of the evaluation of research institutes of the National Academy of Sciences of Ukraine in 2016-2017. The first results of evaluation are discussed and the ways for solving existing problems are proposed.

\section{BACKGROUND OF THE NEW EVALUATION PROCEDURE FOR NASU}

National Academy of Sciences of Ukraine is the leading research organization of the country. It includes 153 research organizations, which form 3 sections and 14 departments according to the distribution of institutes on scientific disciplines. The Academy has 15.6 thousand Researchers; its total budget was 2.8 billion Hryvna Ukr. (2017).

NASU has a relatively high reputation in the country and abroad. The majority of Ukrainian journals from the Web of Science database are published by NASU. However, the Academy has also preserved some features from the Soviet bureaucratic organization, which provokes criticism in society and from foreign experts. Most critics refer to the obsolete managerial system and insufficient transparency in decision-making processes, including distribution of research funds. In fact, NASU is the last remaining part of the Ukrainian research system, which preserved some scientific potential, while Ukrainian science has shrunk substantially in the period of independence (National Academy, 2018). Overall, the number of researchers dropped by more than five times between 19902017, while GERD declined from almost $3 \%$ to $0.45 \%$ in the same period.

The idea of evaluation was to assess the real potential of research institutes, to pick up the best research organizations, to help to better understand problems of these organizations, and to develop corresponding recommendations for changes within NASU. However, the evaluation could have impact not on the Academy itself. If successful, a similar approach to evaluation could be extended to other research institutes of the state sector. At the same time, Ukrainian experience could be useful for some other countries, especially from Eastern Europe and Eurasia, which are trying to reform their research systems.

In 2015, the decision was taken to change the procedure of evaluation of the institutes of the National Academy of Sciences in the context of a general reform of the Ukrainian scientific system. The new evaluation procedure had a variety of aspects that were considered necessary to take into account. It was the intention to base the new evaluation scheme on international experience using both national and international indicators. Further it should have transparent and democratic procedures 
to exclude conflicts of interest, to give the evaluated research organization the possibility to appeal the evaluation results, to be more flexible by not using only one indicator for ranking. Further, the involvement of external evaluators was considered as a key precondition of success. In the course of time, Ukraine decided to utilize the German experience of the Leibniz Association due to a similar organization of the Leibniz Association and the National Academy in many respects. The German Leibniz Association and the National Academy of Sciences of Ukraine have also some similarities in their main directions of activities that open the way for implementation of the positive experience of organization of evaluation in Leibniz Association research organizations in Ukraine. The NASU and the Leibniz Association have research institutes in different scientific disciplines and institutes of multi-disciplinary profiles. Both rely predominantly on public funding as the main source of their activities. The NASU is larger than the Leibniz Association in terms of research personnel, and the number of institutes (Leibniz Association, 2016), while Leibniz Association has a larger budget (approximately 4-5 times larger in purchasing power parities) (World Bank, 2017). The institutes of NASU have a number of difficulties inherited from the Soviet times and greatly aggravated in the last 25 years, especially in the financial sphere. This means that they urgently need structural changes to provide a more rational distribution of scarce money to improve performance and to justify potential increase of state support. The Leibniz Association has substantial experience in transformation and integration of research organizations, because a number of its institutes stem from the research institutes of the GDR and the "Blaue Liste" institutes of West Germany. For these reasons, Leibniz Association serves as an international reference for establishing a new evaluation scheme for NASU in Ukraine.

Before reforming the evaluation procedure in Ukraine, the solely responsible actor for evaluation was the Presidium of the NASU. All research institutions which received public funding were subject to evaluation. The evaluations took place every five years, and were relevant for the institutions to be included in the state register of scientific institutions. The evaluation included a survey of scientific organizations and the supporting technical institutions, the evaluation at the department level collecting additional information, and the checking of the surveyed forms. At the level of the presidium, multidisciplinary expertise was taken into account and resulted in the ranking of the research institutions. The survey included information on aspects such as employee structure, main scientific outputs, applications of results in practice, financing, the extent of scientific and technical services, recognition of results on the national and international level, the number of foreign grants and embeddedness in the scientific community.

The indicators are surveyed on a quantitative level and were weighted using weighting factors, resulting in one final number as a result and a corresponding rank. The state certification of research institutions was the result of the evaluation procedure. The importance resulted out of the fact that this certification war necessary for the inclusion in the state register of scientific institutions.

\section{POLICY DESIGN, APPROACH, METHODOLOGY OF NEW EVALUATION PROCEDURE}

The new NASU approach has some key principles (Metodika, 2017). One is that international experience as well as both national and international indicators are used. Secondly, the evaluation procedures are conducted more transparent, and potential conflicts of interest are systematically being avoided. Thirdly, the research organization has the possibility to question the procedure and results of evaluation. Further, the procedure is being made more flexible by not depending on a single indicator for ranking as it was the case before in the evaluation procedure of NASU. Finally, external, and in best case including foreign, evaluators are involved now (Evaluation Standards, 2015).

There are three stages of evaluation procedure. At the first stage, the expert group (first-level review board, which consists of 5-6 experts) evaluates the scientific activities of the institution. The members of the group inspect the institution's activities, analyze the inquiry form filled by the institution beforehand, verify whether the materials submitted by the institution are unbiased, and prepare their conclusion according to the selected criteria. At the second stage, the Permanent Expert Committee on a Relevant Field of Science (second-level review board) prepares a presentation on the institution activities in accordance with the report of the first-level group and after consultations with the institution. The second-level review board conveys the conclusion of the first-level group to the institution. The institution can make a statement concerning this conclusion. At the third stage, the Permanent Evaluation Committee of the National Academy of Sciences of Ukraine (third-level review board) considers the presentation of the second-level board, the conclusion of the first-level group, and the statement of the institution. The third stage of the evaluation should result in the report of the third-stage review board that should evaluate the scientific activities of the institution and contain recommendation on its further financing. The report of the thirdstage review board should be based on the results of the first-level and second-level evaluation stages. The institution has the following opportunities to take part in the evaluation procedure: prior to the selection of experts of the first-level review board by the second-level review board; the institution can propose a list of main research fields to be covered by the evaluation procedure; the institution can propose experts in these research fields according to the criteria that avoid a potential conflict of interest; following the selection of experts of the first-level review board by the second-level review board, the institution can comment on whether the experts cover the research fields named by the institution; the institution can comment on whether it sees a potential conflict of interest among the experts selected. In case the second-level review board and the institution fail to reach an agreement after the discussion of the comments, the final decision should be made by the first-order review board. The institution obtains a mandatory copy of the first-level review board conclusion from the second-level review board and it is obliged to prepare its statement concerning the conclusion of the first-level review board.

Criteria for evaluation of the quality of work and the potential of an institution by the first-level review board are: development of the institution in previous years and its research strategy for the next years; 
scientific results; scientific events and public outreach; appropriateness of facilities/financial provision. Special attention is paid to collaboration and networking (several positions are usually considered).

The second and the third level review boards take into account such criteria as importance of the institute for the development of the country, its role in the national economy, potential at the international level, perspectives and dynamics of research in corresponding scientific discipline and some other issues. Strategic significance of the institution is determined by answering the following questions as a result of the evaluation: is the institution of strategic significance: for the further development of a specific scientific discipline and its environment? As a hub for specialists or regional clusters? For the further development of fields of technology, information and other services, consulting, socio-political tasks? for the profiling of programs of the NASU?

Key quantitative indicators of evaluation are the following: number of publications (depending on the publication culture of the subject area, in particular in peer-reviewed journals, at peer-reviewed conferences, in monographs etc.); number of documents on commercial property rights and patents, the number of consulting contracts and expert reviews; the amount of third party funds raised for research, consulting, services, etc.; the income from commercial activity such as leasing. Other quantitative indicators could be also included into the evaluation procedure. Quality assurance of evaluation is provided by the a) internal quality management at the institution and b) by assessment of the institution by the relevant Department of NASU.

As a result of the evaluation, the institute could be assigned to one of four groups (in fact, 3 groups, as the last one deals with 'supportive' organizations) according to the level of evaluation results.

NASU created a special Evaluation Office to facilitate the process of evaluation in 2017, which was responsible for the organization of the evaluation and consultative services for expert groups and review boards.

The new evaluation procedure of NASU is strongly oriented towards avoiding conflicts of interest. Here NASU has tried to apply the same criteria as the Leibniz Association (no joint projects, no membership in the scientific boards and joint publications during the last five years etc.). However, due to limited monetary and competence resources, not every small conflict of interest can be fully avoided to maintain a high level of competence among the experts. To solve this, a wider scope of potential experts and more monetary resources for inviting experts would be needed. For example, it is simply not possible to invite best fitting experts from abroad (Western Europe, USA), because of budget constraints.

\section{RESULTS OF THE EVALUATION OF NASU RESEARCH INSTITUTES}

In 2016 first 13 institutes (one from each Department of NASU) were reviewed. Twenty seven other institutes were added to this list in 2017. There are plans to conduct evaluation of 47 institutes in 2018 and the rest of the Academy in 2019. Thus, it is expected that more than half of the NASU institutes will be evaluated until the end of 2018.

It is too early to make final conclusions, but the results of the evaluation of 40 institutes in 2016-2017 and unfinished evaluation of approximately the same number of institutes in 2018 , open the way for some important remarks.
Evaluation in 2016-2018 was useful for both the NASU and the institutes. Some objective information about the situation within the institutes was received, and corresponding recommendations on how to change it were made. This is definitely a positive moment.

However, a number of problems of evaluation have been revealed. More than half of the institutes received the highest mark for their scientific activities. In some cases, review boards had to correct the marks, made by the expert groups.

Evaluation itself revealed a number of barriers for the development of Ukrainian science that need to be overcome.

Like many scientific organizations in transition economies, NASU faces a problem of aging personnel caused by the ongoing emigration of young scientists mainly because of the limited attractiveness of the Ukrainian science system. This is not a particularity of the NASU, but a general difficulty of the science system. Low wages and unclear career tracks attract young and excellent scientist to other areas within the country or abroad. A strong challenge for the NASU is how to attract young scientists into the Ukrainian system of research. The solution requires a broader approach that includes wage policy and academic career tracks. It is an important field for coordination between different fields of policy making.

An example for a fundamentally problematic indicator for the Ukrainian situation is the generation of publication data from databases such as Web of Science or Google Scholar due to differences in the writing of names (transcription), which deteriorates the proper assignment of publications. Further, in different disciplines the assessment of publications and output has to be adjusted. For example, in some areas the revision, commenting and reprinting of classic writings is regular part of the scientific work and output, however hardly to be accounted for if e.g. mainly publications in journals are considered. In other areas the policy consultancy may be part of the regular work and output. These differences in the specific way of working have to be taken into account for a proper and expedient consideration of criteria and indicators. Just using certain publication types would be problematic to take differences between excellence and relevance into account, such as in the case of consultancy activities. Further, to not confuse quantity with quality the review of best publications should be taken into account, alongside with full publication lists.

The second problem is the implicit or explicit hierarchy of criteria and indicators. In several evaluation systems many indicators are imposed but only some really "count" in institutional evaluations. These are normally articles in refereed journals and third-party funding. It is very important to clarify these questions beforehand.

The key issue of the importance of different aspects peaks in the weighting question of indicators. To properly take into account the relevant qualitative and quantitative aspects, as well as the institutional individuality of each institute with corresponding institute specific goals, experts are strongly needed. Further, an involvement of peers may be beneficial to further balance out the weighting process.

The issue of problematic metrics for research assessment is already debated. A closer evaluation of appropriate and inappropriate use of quantitative indicators is regarded, including the conceptualization of "responsible metrics". A framework of five dimensions is available to assess appropriate uses of quantitative indicators:

- robustness: to base metrics on the best possible data regarding accuracy and scope 
- humility: qualitative expert assessment should be supported by quantitative evaluation, but not supplanted

- transparency: transparency and openness of analytical processes, to allow verification by those who are evaluated

- diversity: usage of a variety of indicators to account for the variety of research fields

- reflexivity: recognizing systemic and potential effects of indicators and accordingly updating them (Wilsdon et al., 2015).

It should not be forgotten that the evaluation procedure can shape the mission, developments and working styles of institutes also in a negative way when obeying to certain indicators becomes more important than doing proper discipline specific work. These considerations call for a cautious application of quantitative indicators as well as an increasing importance of qualitative factors. In the evaluation of institutes, some structural factors must not be lost out of sight, such as if a context of structural reforming is given as well as the structural context of institutes for regions. If internal development processes are taking place, it is of major importance to not rise a trade-off situation between learning and evaluation, but instead take learning successes and learning processes which are put into place into account. Thus, evaluations which are only based on a certain point of time should be avoided, and the long-term development of the institute should be kept in mind. Hence, it is critical to take new orientations and priorities that the institute is setting into account, and check whether these are in line with national priorities. Also, short and long-term priorities of the institute and the NASU need to be identified and properly accounted for. Further, to strengthen the development aspect in evaluation the institute could, potentially in cooperation with NASU, conduct a SWOT-Analysis as one possibility for a self-assessment procedure to identify needs for the further development which should be put into practice. Hereby it should be made possible to take the developmental success and changes of the institute more explicitly into account at the next evaluation. Internal assessments are generally a very fruitful preparation for external evaluation. In-depth SWOT analysis could be useful for more precise evaluation of the Ukrainian research institutes.

There were also problems, which were identified with the procedure of evaluation:

1. Formally, experts had no conflict of interest in evaluating the research institutes. They had to sign special forms and the office of Evaluation checked all candidates on co-authorship and participation in joint projects. Unfortunately, it is almost impossible to provide real independence of experts within the relatively closed Ukrainian research system, while the country had no resources to invite a number of foreign experts. Usually, expert groups included not more than one foreign expert. Some of them could not take part in the evaluation procedure at all. Ukraine needs assistance in provision of independent experts for evaluation and participation of foreign experts in evaluation procedures. There are several options for solving this problem. First, initiation of a technical assistance project from the side the EU. The second is to involve representatives of Ukrainian scientific diaspora more actively. The third is to try to ask the government to provide extra funds for the evaluation. The office of Evaluation along with the management of the Academy has made some steps in these directions, including attracting experts from Ukrainian scientific diaspora. However, the results are still not clear.

2. There is a need to improve the list of specific indicators to make them more relevant to the reality of scientific activities of research institutes in different disciplines, as some important activities are not considered by the evaluation. This work is under way with the help of expert groups from different scientific disciplines.

3. The time for the preparation of the report of the institutes and the expert conclusions have to be extended. At the moment, it is 2-3 times shorter than in the Leibniz Association. Such extent could help to improve the quality of evaluationrelated documents.

4. The focus has to be shifted to the research units. This will help to provide internal reorganization of research institutes.

5. A formal procedure has to be proposed to 'appreciate' the best institutes and units. At the moment, it is still not clear, what kind of extra benefits institutes could receive 'automatically' in the case of high marks.

6. Despite strong recommendations to consider the possibility of mergers of relatively small research organizations, this did not take place in the last two years. However, there is a clear need to continue to optimize the network of scientific institutions and organizations. In particular, the consolidation of institutions and the merger of institutions with similar profiles are relevant, as this could help to reduce administrative costs and to improve the general positions of the institute by reorganizations of weak units. Analysis of the existing situation within research institutes shows that a quarter of them have less than 20 researchers, some units have 3-5 persons only, including supportive staff. A number of them do not have specialists with highest academician degrees. Such reorganization could help to preserve important research areas and human resources, taking into account such aspects as the relevance of research topics, specific results - scientific publications, patents, licenses, etc.

The work on improvement of evaluation is under way now and the Ministry of Education and Science of Ukraine has announced plans to utilize the experience of NASU for other research organizations including those, subordinated to Ministry of Education and Science, in 2019.

\section{REFERENCES}

European Commission (2016). Background Report. Peer Review of the Ukrainian Research and Innovation, Horizon 2020 Policy Support Facility.-Luxembourg: Publications Office of the European Union.

Platform for Research and Technology Policy Evaluation (2015) Evaluation Standards in Research and Technology Policy. Retrieved August 8, 2018 from https://www.fteval.at/.

Metodika otsnuvannia dialnosti naukovyh ustanov NASU (2017) Retrieved August 10, 2018 from: http://www.nas.gov.ua/text/pdfNews/ metodyka_text.pdf (in Ukrainian) 
Leibniz Association: key figures (2016) - Retrieved August 22, 2018

from: https://www.research-in-germany.org/en/research-landscape/ research-organisations/leibniz-association.html

National Academy of Sciences of Ukraine in 2017 (2018) Kyiv: NASU (in Ukrainian)

Naukova y naukovo-tehnichna Diyalnist v Ukraini (2017) - State Statistical Service of Ukraine: Statistical Yearbook (in Ukrainian)

Wilsdon, J., Allen, L., Belfiore, E., Campbell, P., Curry, S., Hill, S., Jones, R., Kain, R., Kerridge, S., Thelwall, M., Tinkler, J., Viney, I. and Wouters, P. (2015): The metric tide: Executive summary - Report of the Independent Review of the Role of Metrics in Research Assessment and Management. HEFCE.

World Bank data (2017) Retrieved July 15, 2018 from: https://data. worldbank.org/indicator/NY.GDP.PCAP.PP.CD

\section{AUTHOR}

\section{IGOR YEGOROV}

Office of Evaluation and Institute of Economy and Forecasting, National Academy of Sciences of Ukraine

26 Panasa Myrnogo st., Kiev, 01011, Ukraine

E: Igor yegorov1@ukr.net

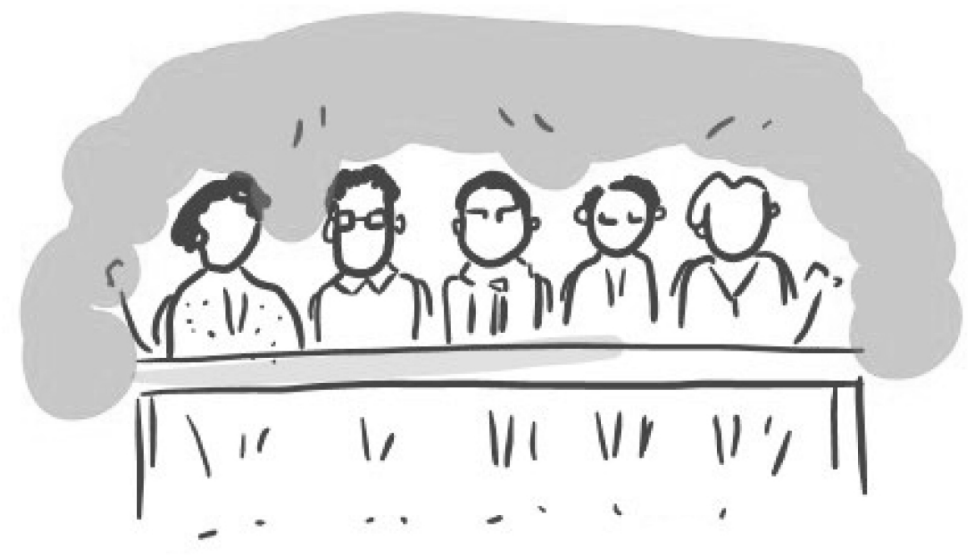

